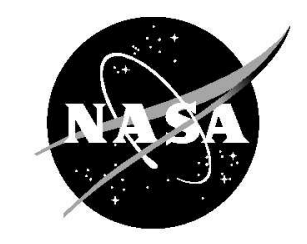

\title{
Phased Array Noise Source Localization Measurements Made on a Williams International FJ44 Engine
}

Gary G. Podboy

Glenn Research Center, Cleveland, Ohio

Csaba Horvath

ASRC Aerospace Corporation, Cleveland, Ohio 


\section{NASA STI Program . . . in Profile}

Since its founding, NASA has been dedicated to the advancement of aeronautics and space science. The NASA Scientific and Technical Information (STI) program plays a key part in helping NASA maintain this important role.

The NASA STI Program operates under the auspices of the Agency Chief Information Officer. It collects, organizes, provides for archiving, and disseminates NASA's STI. The NASA STI program provides access to the NASA Aeronautics and Space Database and its public interface, the NASA Technical Reports Server, thus providing one of the largest collections of aeronautical and space science STI in the world. Results are published in both non-NASA channels and by NASA in the NASA STI Report Series, which includes the following report types:

- TECHNICAL PUBLICATION. Reports of completed research or a major significant phase of research that present the results of NASA programs and include extensive data or theoretical analysis. Includes compilations of significant scientific and technical data and information deemed to be of continuing reference value. NASA counterpart of peer-reviewed formal professional papers but has less stringent limitations on manuscript length and extent of graphic presentations.

- TECHNICAL MEMORANDUM. Scientific and technical findings that are preliminary or of specialized interest, e.g., quick release reports, working papers, and bibliographies that contain minimal annotation. Does not contain extensive analysis.

- CONTRACTOR REPORT. Scientific and technical findings by NASA-sponsored contractors and grantees.
- CONFERENCE PUBLICATION. Collected papers from scientific and technical conferences, symposia, seminars, or other meetings sponsored or cosponsored by NASA.

- SPECIAL PUBLICATION. Scientific, technical, or historical information from NASA programs, projects, and missions, often concerned with subjects having substantial public interest.

- TECHNICAL TRANSLATION. Englishlanguage translations of foreign scientific and technical material pertinent to NASA's mission.

Specialized services also include creating custom thesauri, building customized databases, organizing and publishing research results.

For more information about the NASA STI program, see the following:

- Access the NASA STI program home page at http://www.sti.nasa.gov

- E-mail your question via the Internet to help@ sti.nasa.gov

- Fax your question to the NASA STI Help Desk at $443-757-5803$

- Telephone the NASA STI Help Desk at 443-757-5802

- Write to: NASA Center for AeroSpace Information (CASI) 7115 Standard Drive Hanover, MD 21076-1320 


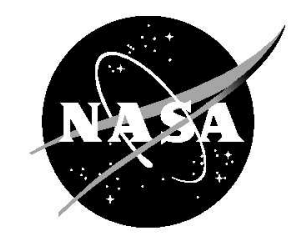

\section{Phased Array Noise Source Localization Measurements Made on a Williams International FJ44 Engine}

Gary G. Podboy

Glenn Research Center, Cleveland, Ohio

Csaba Horvath

ASRC Aerospace Corporation, Cleveland, Ohio

Prepared for the

15th Aeroacoustics Conference (30th AIAA Aeroacoustics Conference) cosponsored by AIAA and CEAS

Miami, Florida, May 11-13, 2009

National Aeronautics and

Space Administration

Glenn Research Center Cleveland, Ohio 44135 
Trade names and trademarks are used in this report for identification only. Their usage does not constitute an official endorsement, either expressed or implied, by the National Aeronautics and Space Administration.

This work was sponsored by the Fundamental Aeronautics Program at the NASA Glenn Research Center.

Level of Review: This material has been technically reviewed by technical management.

Available from

NASA Center for Aerospace Information 7115 Standard Drive

Hanover, MD 21076-1320
National Technical Information Service 5301 Shawnee Road Alexandria, VA 22312

Available electronically at http://gltrs.grc.nasa.gov 


\title{
Phased Array Noise Source Localization Measurements Made on a Williams International FJ44 Engine
}

\author{
Gary G. Podboy \\ National Aeronautics and Space Administration \\ Glenn Research Center \\ Cleveland, Ohio 44135 \\ Csaba Horvath \\ ASRC Aerospace Corporation \\ Cleveland, Ohio 44135
}

\begin{abstract}
A 48-microphone planar phased array system was used to acquire noise source localization data on a full-scale Williams International FJ44 turbofan engine. Data were acquired with the array at three different locations relative to the engine, two on the side and one in front of the engine. At the two side locations the planar microphone array was parallel to the engine centerline; at the front location the array was perpendicular to the engine centerline. At each of the three locations, data were acquired at eleven different engine operating conditions ranging from engine idle to maximum (take off) speed. Data obtained with the array off to the side of the engine were spatially filtered to separate the inlet and nozzle noise. Tones occurring in the inlet and nozzle spectra were traced to the low and high speed spools within the engine. The phased array data indicate that the Inflow Control Device (ICD) used during this test was not acoustically transparent; instead, some of the noise emanating from the inlet reflected off of the inlet lip of the ICD. This reflection is a source of error for far field noise measurements made during the test. The data also indicate that a total temperature rake in the inlet of the engine is a source of fan noise.
\end{abstract}

\section{Introduction}

Significant noise reduction will be required in order for commercial aircraft to meet future noise regulations. Consequently, the development of noise reduction technologies for subsonic commercial aircraft is a major focus of the Subsonic Fixed Wing Project in NASA's Fundamental Aeronautics Program. The turbofan engines which power these aircraft generate much of the total noise produced by the aircraft. Therefore, efforts to reduce aircraft noise must also include efforts to reduce engine noise.

In 2008, under the Innovative Partnerships Program, NASA entered into a cost-sharing agreement with Williams International to test a Williams FJ44 engine at the Aero-Acoustic Propulsion Laboratory (Ref. 1) (AAPL) at the NASA Glenn Research Center. There were two primary objectives of the test. The first was to obtain acoustic data that could be used to determine the extent to which a foam metal acoustic liner placed in the fan duct very close to the fan tip could reduce fan noise relative to a conventional hardwall inlet. To meet this objective, far field acoustic data were acquired during separate engine runs in which the foam metal and conventional hardwall liners were installed. These data indicate that the foam metal liner was very effective at reducing fan broadband noise, especially when the fan was operating at subsonic tip speeds. Details regarding the far field acoustic results are presented by Sutliff, et al. (Ref. 2). An overview of the FJ44 test in the AAPL is presented by Lauer, et al. (Ref. 3).

The second test objective was to obtain diagnostic data that could provide a better understanding of the dominant noise production mechanisms inside the engine. Diagnostic data were acquired with a rotating microphone rake mounted in the inlet, an axial array of unsteady pressure transducers mounted in the inlet duct upstream of the fan, and with a new, 48-microphone, planar phased array system.

The phased array system, known as Array 48, was developed by OptiNAV, Inc. This FJ44 engine test represented the second use of the Array 48 system at NASA Glenn. The array was first used during a jet 
noise test involving the Small Hot Jet Acoustic Rig located in the AAPL. Results of that jet noise phased array test are presented in a report by Dougherty, et al. (Ref. 4). The objectives of the present paper are to present phased array data acquired on the full-scale Williams engine that 1) demonstrate the capabilities of the Array 48 phased array system, and 2) provide information regarding the dominant noise sources in the engine.

\section{Nomenclature}

$\begin{array}{ll}\text { b } & \text { beamforming result } \\ \text { BPF } & \begin{array}{l}\text { blade passing frequency } \\ c\end{array} \\ \text { the speed of sound } \\ \text { C } & \text { cross spectral matrix } \\ \text { FML } & \text { Foam Metal Liner } \\ \text { g } & \text { steering vector } \\ \text { ICD } & \text { Inflow Control Device } \\ \text { N1 } & \text { Low-pressure spool shaft rotation frequency } \\ \text { N2 } & \text { High-pressure spool shaft rotation frequency } \\ \vec{x} & \text { grid point location } \\ & \text { microphone location } \\ \omega & \text { angular frequency } \\ \mathbf{w} & \text { normalized steering vector }\end{array}$

\section{Apparatus and Procedure}

\section{The Williams FJ44 Engine}

A photograph of the Williams FJ44 engine installed on a support stand in the Aero-Acoustic Propulsion Laboratory at NASA Glenn is shown in Figure 1. The FJ44 is a small, 3,000-lbf (12,500 N) thrust class turbofan engine produced for the light business jet market. The fan blisk contains 16 fan blades. The FJ44 engine has two spools: a low-speed, low-pressure spool made up by a single-stage fan, a three-stage axial compressor, and a two-stage axial turbine; and a high-speed, high-pressure spool composed of a single-stage centrifugal compressor and a single-stage axial turbine. In the rear, the FJ44 has an internal lobed mixer to mix the core and bypass flows.

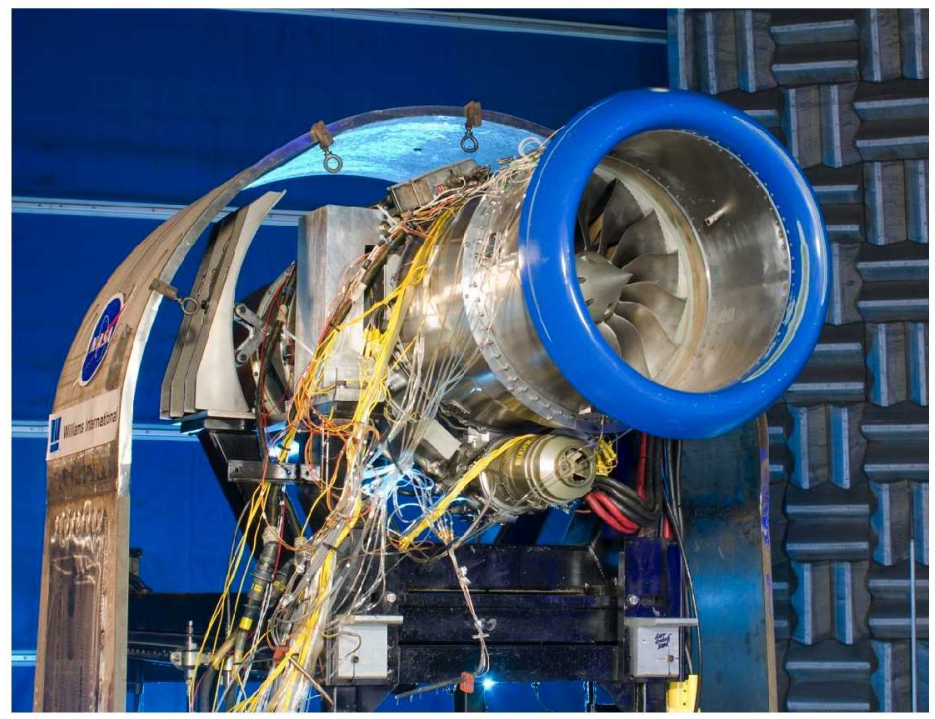

Figure 1.-Photo showing the FJ44 engine installed on a test stand inside the AAPL. 
Two different fan rotors were used during the course of the test. All of the testing, except for the phased array portion, was done with a brand new fan blisk installed within the engine. The phased array testing was done using an old fan rotor that had been used previously during ice ingestion studies. The fan blades were repaired after the ice ingestion test, but this rotor was still expected to generate significant multiple pure tone (MPT) noise. The phased array testing was also conducted with a hardwall inlet installed within the engine (not with the foam metal liner).

\section{The Phased Array System}

Figure 2 shows a photograph of the Optinav Array 48 phased array system used during this test. This system consists of 48 Earthworks M30 electret microphones flush-mounted to a 1 by $1 \mathrm{~m}$ Aluminum plate. The microphones are arranged in a series of log spirals in an effort to reduce sidelobes (errors in the phased array data). These microphones have $1 / 4$ in. diameter diaphragms, a flat frequency response over a frequency range of $5 \mathrm{~Hz}$ to $30 \mathrm{kHz}$, and do not saturate until the sound pressure level reaches $142 \mathrm{~dB}$.

A photograph of the back of the microphone array is shown in Figure 3. This photo shows the microphones mounted to the back of the array plate and a camera located at the center of the plate. There is a hole in the center of the plate through which the camera can be used to take a photo of the "field of view" of the phased array system. The phased array data reduction software superimposes the acoustic source localization data on top of the image taken with the phased array camera.

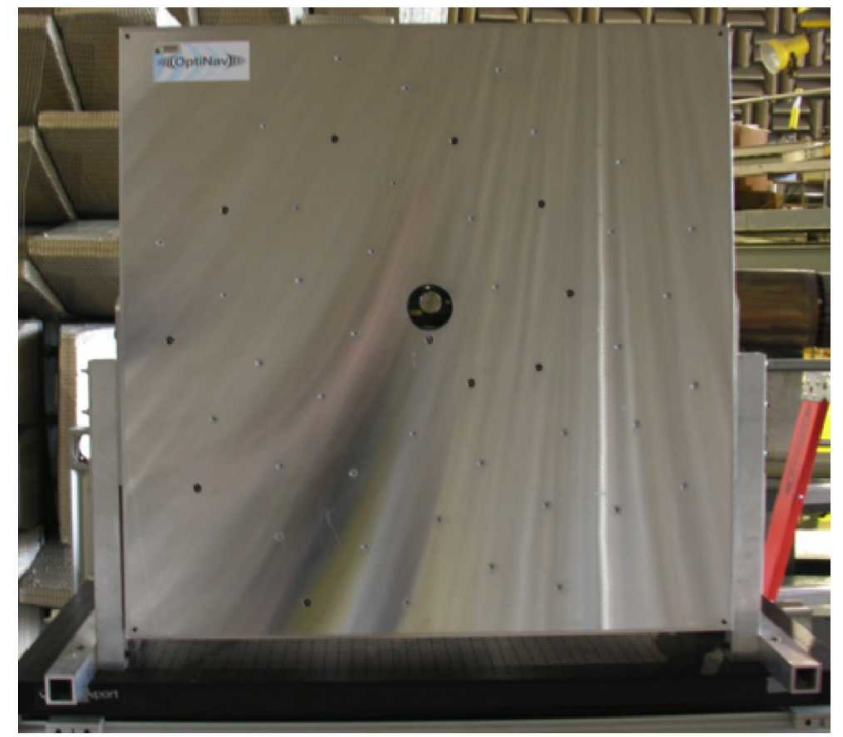

Figure 2.-Photo showing front view of the Arrray48 phased array system.

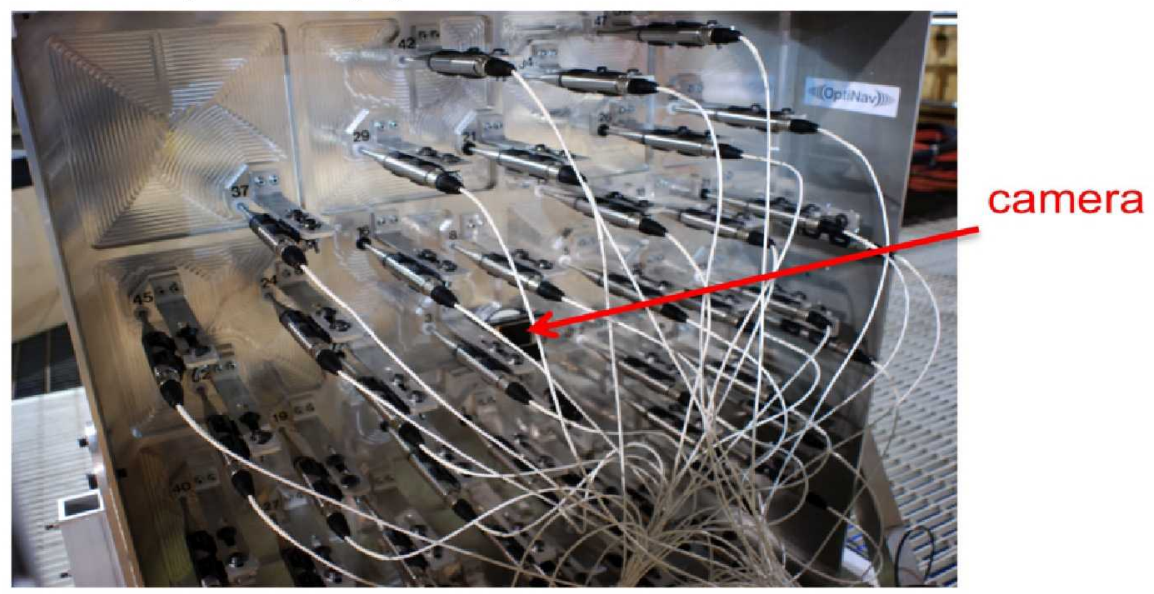

Figure 3.-Photo showing rear view of the Arrray48 phased array system. 
The phased array data were reduced using classical beamforming in the frequency domain.

The first step in the data reduction process was to compute the cross spectral matrix, $\mathrm{C}$, from the array data using the periodogram method with Hanning windowing functions and 50 percent block overlap. The diagonal elements of the cross spectral matrix are then deleted (yielding $\overline{\mathrm{C}}$ ), and the beamforming result, $b$, at a given grid point, $k$, is computed using the classical beamforming expression

$$
b_{k}=\mathbf{w}_{\mathbf{k}}^{\prime} \overline{\mathbf{C}} \mathbf{w}_{\mathrm{k}}
$$

where $\mathbf{w}_{\mathbf{k}}$ is a normalized version of the steering vector $\boldsymbol{g}_{k}$. The individual elements of $\boldsymbol{g}_{k}$ represent the Green's function for a monopole located at grid point $k$ as observed by microphone $i$. In free space with no flow

$$
\boldsymbol{g}_{k i}=\frac{e^{j \frac{\omega}{c}\left|\vec{y}_{i}-\vec{x}_{k}\right|}}{\left|\vec{y}_{i}-\vec{x}_{k}\right|}
$$

where $\vec{x}_{k}$ and $\vec{y}_{i}$ denote the locations of grid point $k$ and microphone $i$, respectively. A beamforming result is computed for each point in a beamforming grid. The results corresponding to an entire grid are then displayed as color contour maps (known as beamform maps).

The output of the phased array data reduction routine is a stack of beamform maps. Each beamform map in the stack corresponds to a different frequency band. Each beamform map shows the location of the dominant noise source or sources in a frequency band as a 2D color contour map overlaid on top of a photograph taken with the phased array camera. The color contours correspond to the location and strength of the noise sources found within an image plane (the beamform grid) at some specified location away from the microphone array. The user selects the location of the image plane by specifying a microphone-array-to-image-plane distance. Usually this image plane is parallel to the microphone array and usually its location is selected to coincide with a region where dominant noise sources are suspected, such as along the centerline of a jet flow. The dynamic range of the color contours (max value minus min value) is the same for each image in the stack, but the peak value varies from image to image. The peak contour level of a given image corresponds to the strength of the dominant noise source within the frequency band associated with that image. The source strength is given in terms of sound power level in $\mathrm{dB}$. The number of images in the stack and the bandwidth corresponding to an image depends on how the data are processed. The data can be processed into one-twelfth octave, one-third octave, octave, narrowband, or kilohertz bands or into only one band.

\section{Test Configurations}

During the test, data were acquired with the microphone array at three different locations relative to the engine. These three locations will be referred to as locations 1,2 , and 3 . They are depicted in the photographs of Figure 4(a), (b), and (c), respectively. As shown in Figure 4(a), at location 1 the array was located at the side of the engine midway between the inlet highlight and the nozzle exit plane. At this location the plate holding the microphone array was parallel to and 193 in. from the engine centerline. Location 1 was chosen so that the phased array could detect or "image" noise coming from both the inlet and the nozzle at the same time. Figure 4(b) shows the array positioned further downstream and closer to the engine centerline at location 2. Here, the array plate was parallel to and $124 \mathrm{in}$. from the engine centerline. The center of the array was $60 \mathrm{in}$. (roughly four nozzle exit diameters) downstream of the nozzle exit plane. The array was closer to the jet centerline at location 2 versus location 1 , therefore it was thought that it would do a better job of imaging the jet noise sources when at location 2. Figure 4(c) shows the array at location 3. Here, the array was at the front of the engine and positioned so that it could detect the noise sources coming from the inlet. At this location the array plate was roughly perpendicular to the engine centerline and approximately $182 \mathrm{in}$. upstream of the fan rotor. At each of the three locations, data were acquired at each of eleven different operating conditions ranging from engine idle to max (take off) speed. 

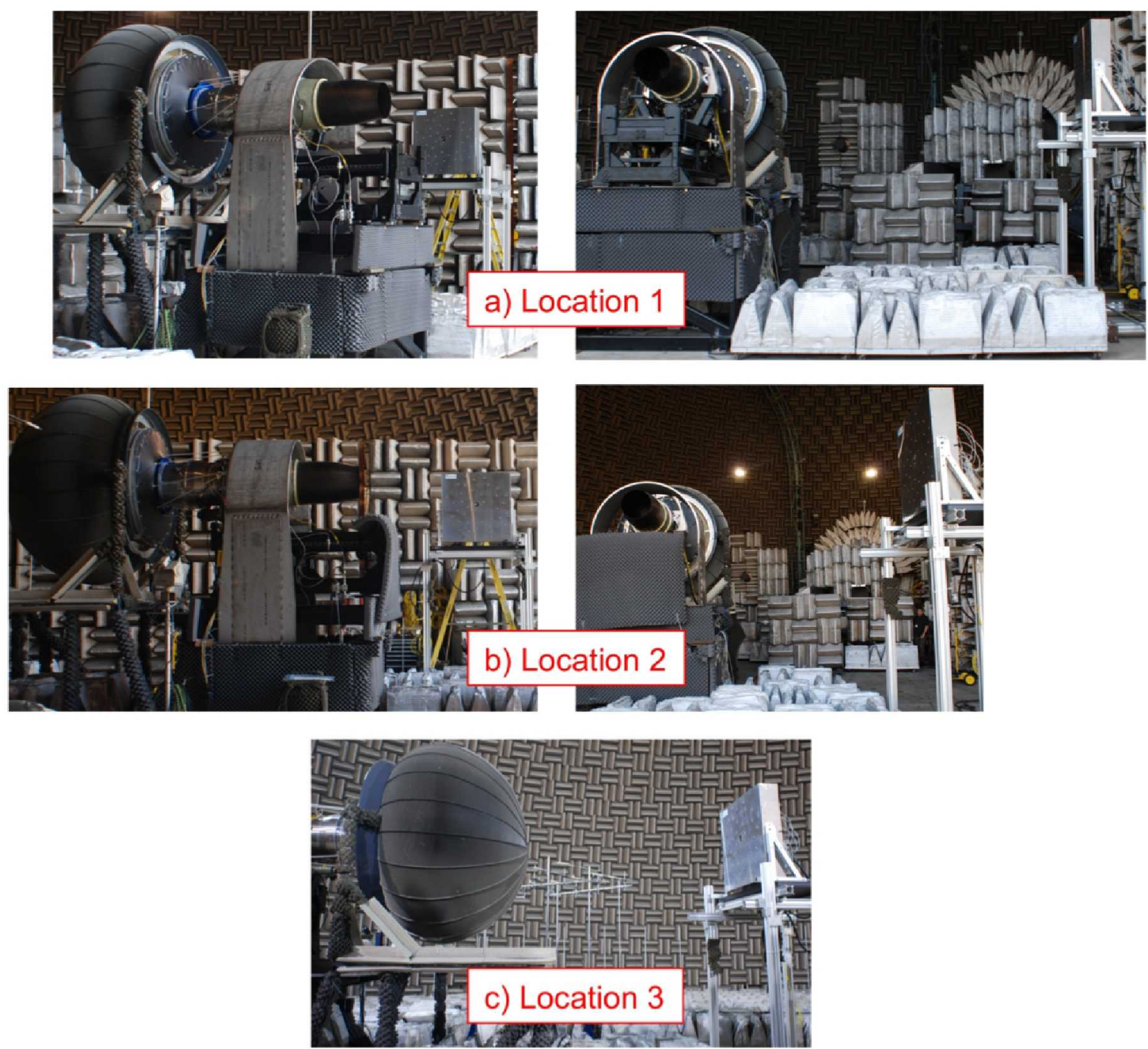

Figure 4.-Photos showing the array at three different locations relative to the FJ44 engine.

\section{Results}

Figure 5 shows an example of phased array data obtained with the array at location 1, at the side of the engine midway between the inlet lip and the nozzle exit plane. Data were acquired with the array at this location so that the array would be able to identify noise coming from both the inlet and the nozzle exhaust flow at the same time. The data were processed in such a way that the data reduction routine searched for noise sources in a vertical plane passing through the engine centerline. Although all of the data obtained during this test were acquired with an inflow control device (ICD) located at the front of the engine as shown in Figure 4, the phased array contour plots provided in Figure 5 are shown overlaid on top of an image that was taken with the phased array camera after the ICD was removed. The data are shown overlaid on top of this image in order to illustrate more clearly where the source localization contours appear relative to the engine inlet. The data presented in Figure 5 were acquired with the fan operating at 85 percent of the engine design (take off) speed. The data were reduced using narrowband processing, and Figure 5 shows eight narrowband images selected from the complete stack of images. 

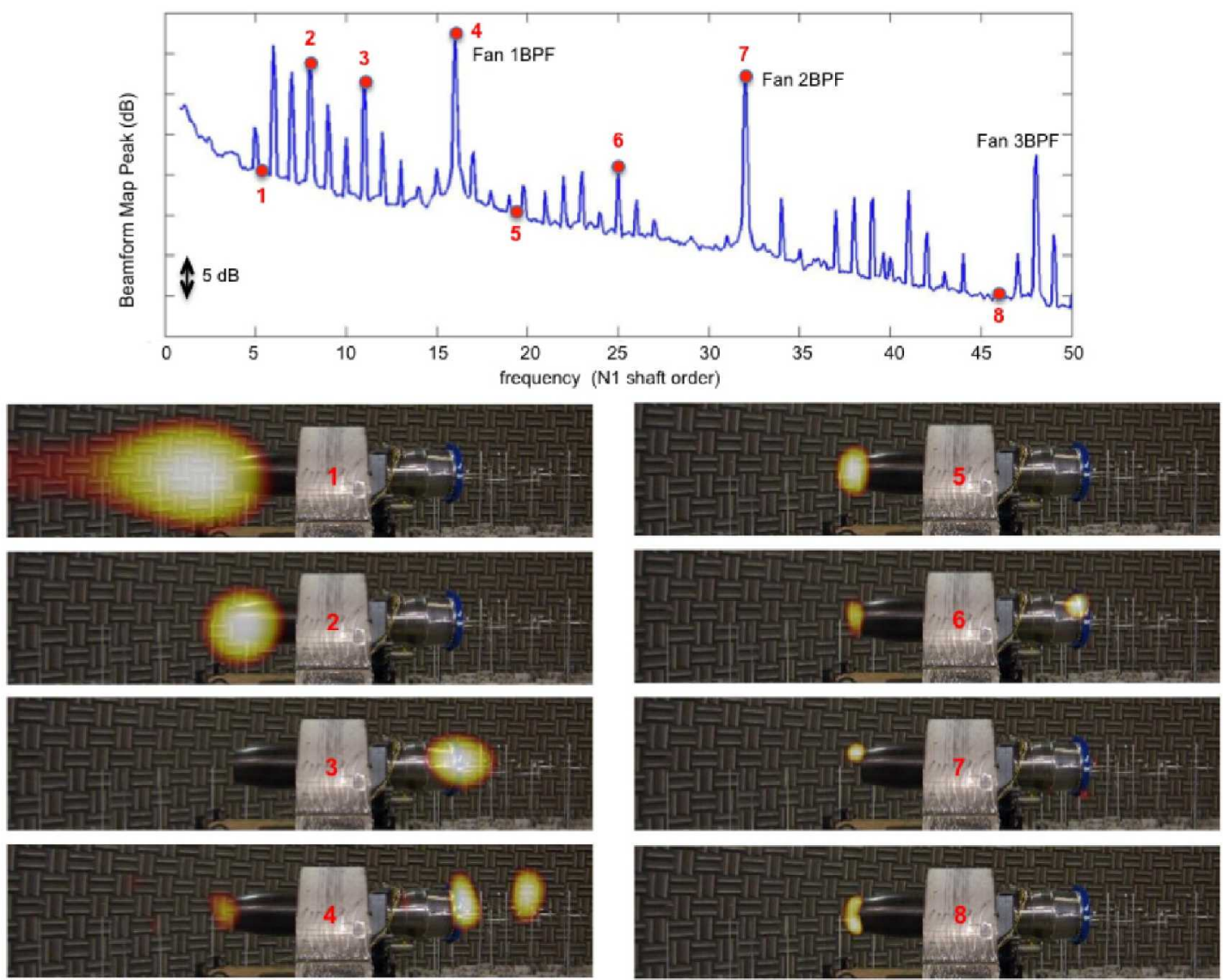

Figure 5.-Phased array data obtained with the array located at the side of the engine with the engine operating at 85 percent speed.

The line plot at the top of the figure shows a spectrum generated from the complete set of narrowband data. It shows the variation of the peak beamform map contour level with frequency (i.e., how the peak contour level varies from one narrowband image to the next over the frequency range). The frequency has been nondimensionalized so that the low speed spool shaft order is plotted along the abscissa. Data are shown for frequencies up to and including 50 shaft orders. The 16-bladed fan was part of the low speed spool, so the fan blade passing frequency (BPF) occurs at shaft order 16. At this operating condition (85 percent speed) the fan tip Mach number is transonic, and strong shocks are expected to propagate into the inlet duct upstream of the fan. Multiple pure tones (MPTs) resulting from blade-to-blade nonuniformities in these shocks appear in the spectrum located at integer multiples of the fan once-perrevolution frequency, $\mathrm{N} 1$.

The peak values occurring in the eight phased array beamform maps and the corresponding narrowband frequencies are designated on the spectra plot by the red dots. For example, the dot labeled no. 1 on the spectra plot corresponds to the phased array image labeled no. 1 provided below the spectrum. Using the contour plot along with the spectra plot allows the determination of both the location of the dominant noise source (from the contour plot) and the type of noise (tone or broadband, from the spectra plot) generated within a given frequency band. For example, the contour plot of image no. 1 shows that the dominant noise source in this frequency band is located downstream of the nozzle exit in the jet, and the corresponding location on the spectra plot shows that this source is generating lowfrequency broadband noise occurring between what appear to be two multiple pure tones. Similar to images nos. 1, 5, and 8, all of the images in the stack for which the dominant source was generating broadband noise indicate that the source was located in the jet flow. In contrast, most of the images associated with tones occurring at integer multiples of the low speed spool shaft order that were not also 
multiples of fan blade passing frequency (i.e., tones which would appear to be multiple pure tones) indicate that the dominant noise source was located in the inlet. This is not unexpected considering that MPTs are thought to be generated by shocks propagating in the inlet upstream from the fan blades. Some MPT-like tones, however, such as that associated with image no. 6, appear to come from both the inlet and the nozzle. The fan 1BPF and 2BPF tones also appear to come from both the inlet and the nozzle. In the case of the 1BPF tone the inlet noise dominates at this operating condition and array location, whereas with the 2 BPF tone the aft noise dominates. Based on its location in the spectra plot, it would appear that the strong tone associated with image no. 2 would be a multiple pure tone. The contour map, however, indicates that the source of this tone appears to be located inside the nozzle.

The data presented in Figure 5 were processed in such a way that the data reduction routine searched for noise sources in a vertical plane passing through the engine centerline at all the locations defined by the extent of the photographic image. A very useful aspect of the data processing software is the ability to search only on smaller subregions in the plane using what are referred to as regions of interest (ROIs). An ROI is a user-defined subregion which serves as a spatial filter. The data reduction software searches for noise sources within the ROI and ignores the sources located outside the ROI. Figure 6 shows two ROIs defined on the photographic image that was shown previously in Figure 5. Figure 6(a) shows an ROI (the red rectangle) over the downstream or nozzle noise producing regions, while Figure $6(\mathrm{~b})$ shows an ROI over the upstream or inlet regions.

By employing ROIs it is possible to quickly compare the strength and frequency content of the sources in one noise-producing region with those in another. Figure 7 shows a comparison of spectra plots obtained using the same raw data that were used to generate the results presented in Figure 5 but reprocessed using the nozzle and inlet ROIs shown in Figure 6. The nozzle spectrum (blue) was generated from noise sources only inside the nozzle ROI, while the inlet spectrum (red) was generated from noise sources only in the inlet ROI. The relative levels of the nozzle and inlet spectra at a given frequency indicate whether sources within the nozzle, inlet, or both are important for that array location. A comparison of these two spectra indicates 1) that the jet is the dominant source of broadband noise over the entire frequency range, 2) that most of the strong, sub-BPF MPT-like tones come from the inlet, 3) that the 1 and 3 BPF tones are stronger from the inlet, 4) that the 2 BPF tone is slightly stronger from the nozzle, and 5) that there is a strong tone occurring near shaft order 8 (near $1 / 2$ of $1 \mathrm{BPF}$ ) that is coming from the nozzle.

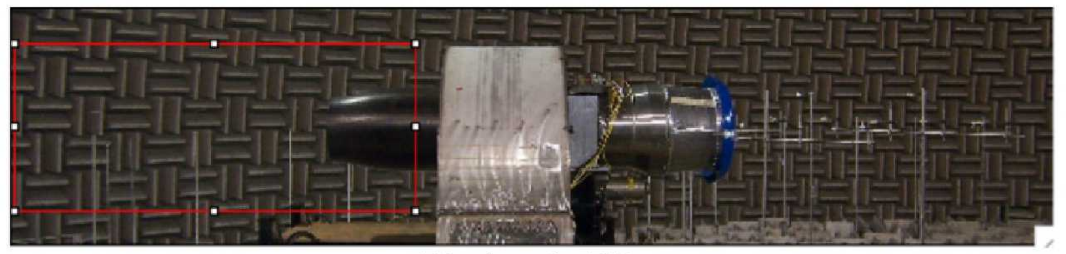

a) Nozzle section $\mathrm{ROI}$

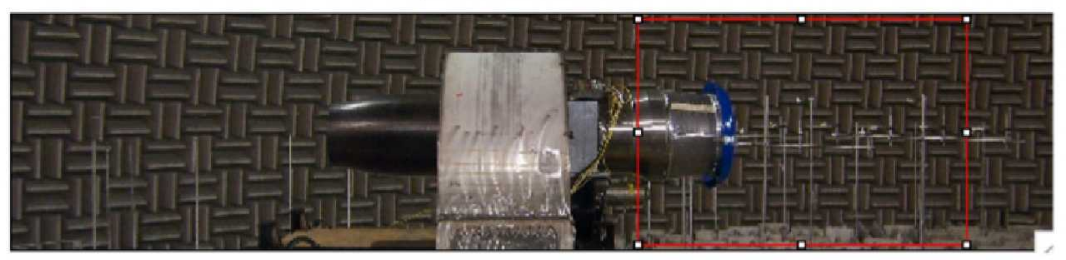

b) Inlet section ROI

Figure 6.-Regions of Interest used to limit the area over which the search for noise sources is conducted. 

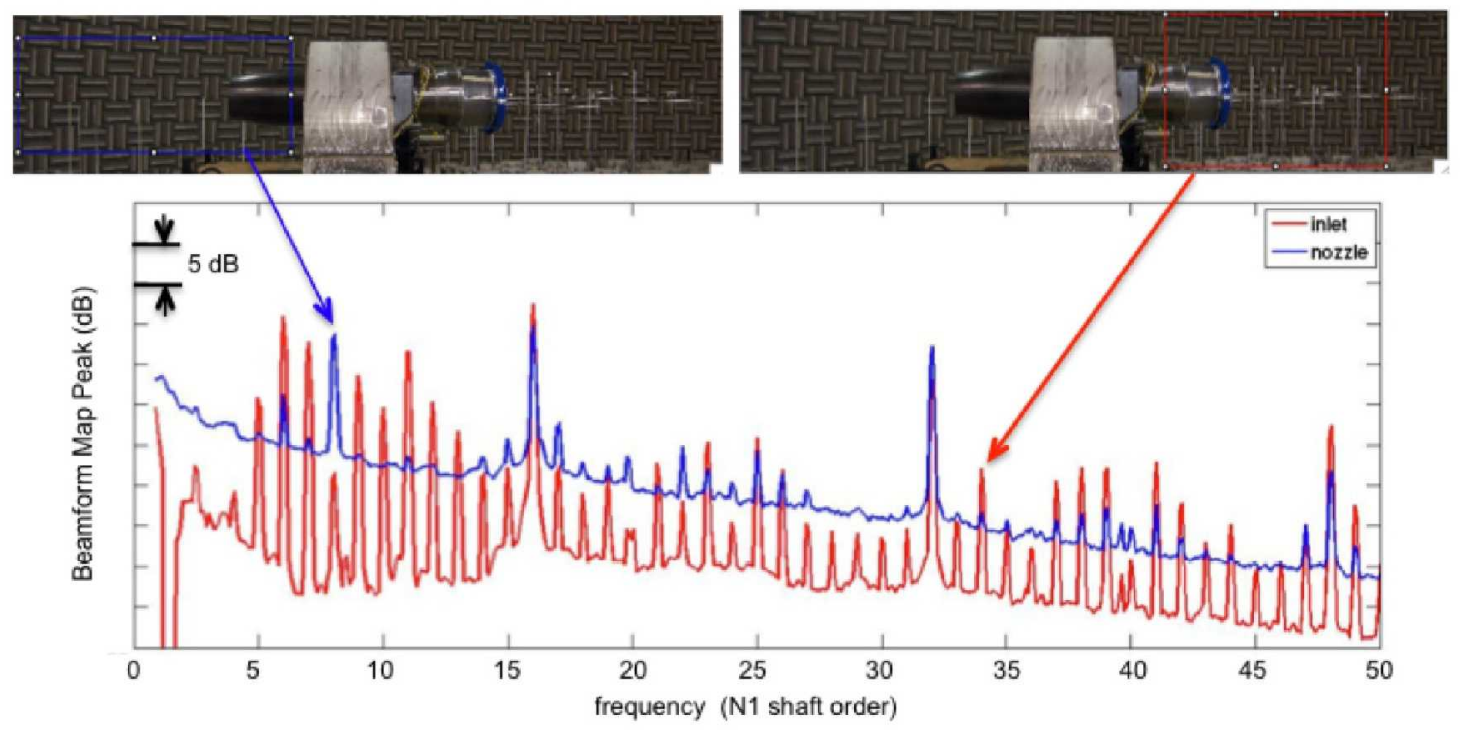

Figure 7.-Beamform map peak spectra resulting from the use of nozzle and inlet ROls ( 85 percent speed).
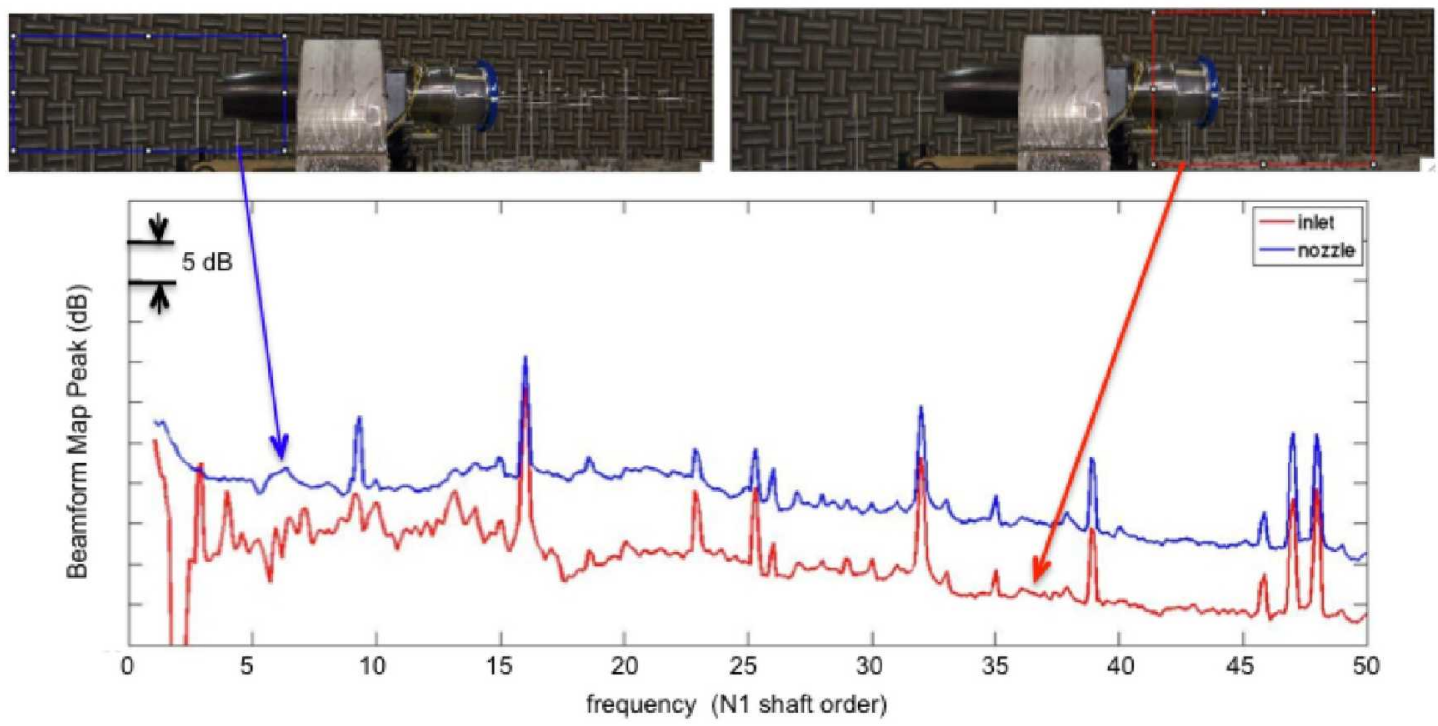

Figure 8.-Beamform map peak spectra resulting from the use of nozzle and inlet ROls (69 percent speed).

Figure 8 shows the same sort of comparison between inlet and nozzle beamform map spectra, but generated from data obtained at a lower fan speed, 69 percent speed. At this rotor speed the fan tip Mach number is subsonic. These spectra indicate that the aft sources dominate the inlet sources over the entire frequency range, regardless of whether the sources are tonal or broadband. As was the case with the 85 percent speed data, the nozzle spectrum (blue) shows a subBPF tone that appears to be generated within the nozzle region. At this lower speed it appears near shaft order 9; at 85 percent speed it was closer to shaft order 8. Since the fan tip speed is subsonic, it is clear that this tone is not an MPT.

After the speed of a fan is increased beyond the point at which the tip becomes sonic, there is a speed range over which MPT noise tends to increase. Normally, however, there comes a point at which further increases in fan speed result in decreased MPT noise. This decrease in MPT noise is thought to coincide with the weakening of the shocks propagating upstream of the blades and with the shocks getting pushed back in the inlet duct toward the rotor fan face (Ref. 5). Figure 9 shows inlet and nozzle beamform map spectra generated from data acquired with the fan operating at the 100 percent speed take off operating condition. At this condition the fan tip is operating at a speed well beyond that at which the tip first becomes sonic. The fan tip speed at this condition is also well beyond that of the 85 percent speed 


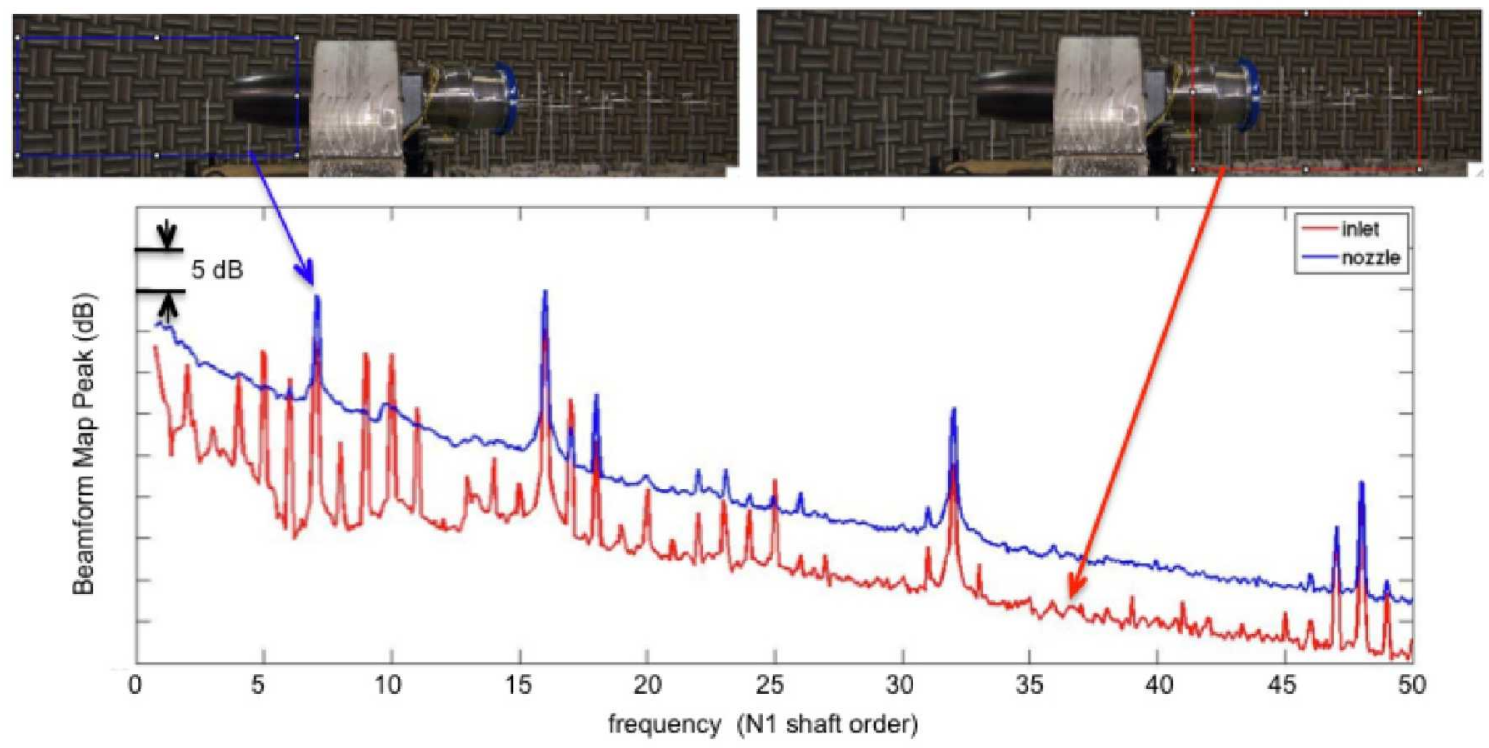

Figure 9.-Beamform map peak spectra resulting from the use of nozzle and inlet ROls (100 percent speed).

operating condition for which the data showed a large number of dominant MPTs coming from the inlet (see Fig. 7). A comparison between the 85 percent (Fig. 7) and 100 percent speed (Fig. 9) spectra indicates that there are fewer dominant MPTs at the higher speed condition. The inlet (red) spectrum of Figure 9 indicates that there are a large number of MPT tones coming from the inlet, but only a few that are higher than the noise coming from the nozzle region (blue). The 100 percent speed spectra plots also indicate that the 1, 2, and 3 BPF tones are stronger from the nozzle than from the inlet. The nozzle spectrum (blue) indicates that the strong sub-BPF tone discussed earlier (now appearing near shaft order 7) is important at this operating condition also.

Figure 10 shows beamform maps generated from data acquired with the microphone array at location 2. At this location the array was parallel to and $124 \mathrm{in}$. away from the engine centerline; the center of the array was $60 \mathrm{in}$. downstream of the nozzle exit plane. As compared to location 1, the array was closer to the jet flow when at location 2. At the closer location, the array was expected to do a better job of imaging (i.e., generate more detailed beamform maps of) the noise sources in the nozzle region. Figure 10 shows $1 / 3$ rd octave beamform maps generated from data obtained at the same three speeds at which data were presented for the array at location $1-69,85$, and 100 percent speed. The exit flow is subsonic at each of these operating conditions; therefore no shocks exist in the jet flow. Consequently, the noise imaged by the array is either jet turbulent mixing noise or noise produced inside the engine that propagates out the nozzle. As expected, the beamform maps show that for a given operating condition the location of the peak turbulent mixing noise moves closer to the nozzle exit with increasing frequency. For frequencies of $5000 \mathrm{~Hz}$ and less the maps also show that within a given octave band the location of the peak turbulent mixing noise moves further downstream of the nozzle exit as the fan rotational and jet flow speeds increase. For frequencies $5000 \mathrm{~Hz}$ and greater, some of the images show prominent noise sources at both a downstream location along the jet centerline and closer to the nozzle exit. The noise imaged near the exit of the nozzle is likely to be a combination of jet turbulent mixing noise and noise produced by other sources within the engine propagating out the nozzle exit. It is thought that at least part of the asymmetry in some of the beamform maps (see the 8000 and $16000 \mathrm{~Hz} 1 / 3 \mathrm{rd}$ octave band images for the 85 percent speed condition) is due to tones produced inside the engine that propagate out the nozzle. It has been observed that beamform maps are often asymmetric when a strong tone is contained within the frequency band of the image; sometimes the contours are not only asymmetric, but they appear at unexpected locations. This indicates that the array has more difficulty locating tonal as opposed to broadband sources. Therefore, extra care should be exercised in interpreting images for which a dominant tone occurs within the frequency band of the image. 


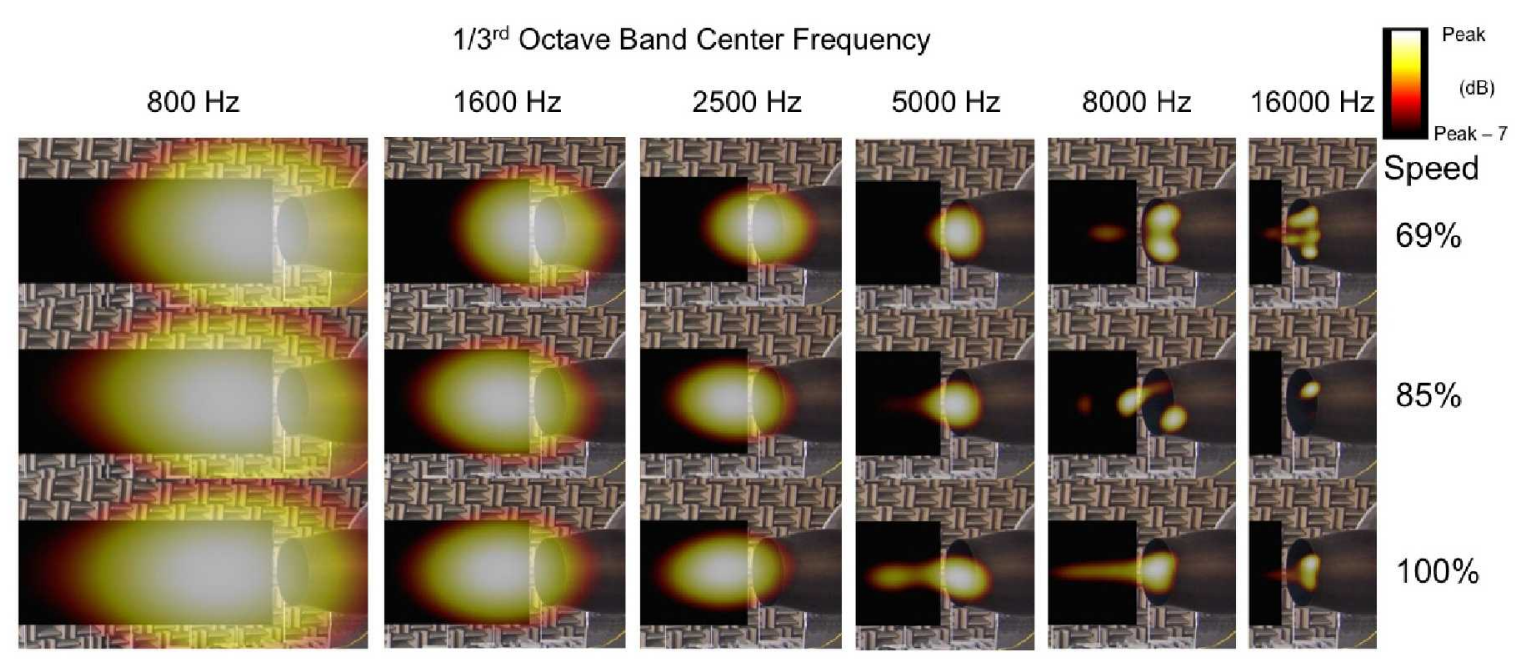

Figure 10.-Beamform maps showing jet noise sources at three engine operating conditions for six different $1 / 3$ rd octave bands.

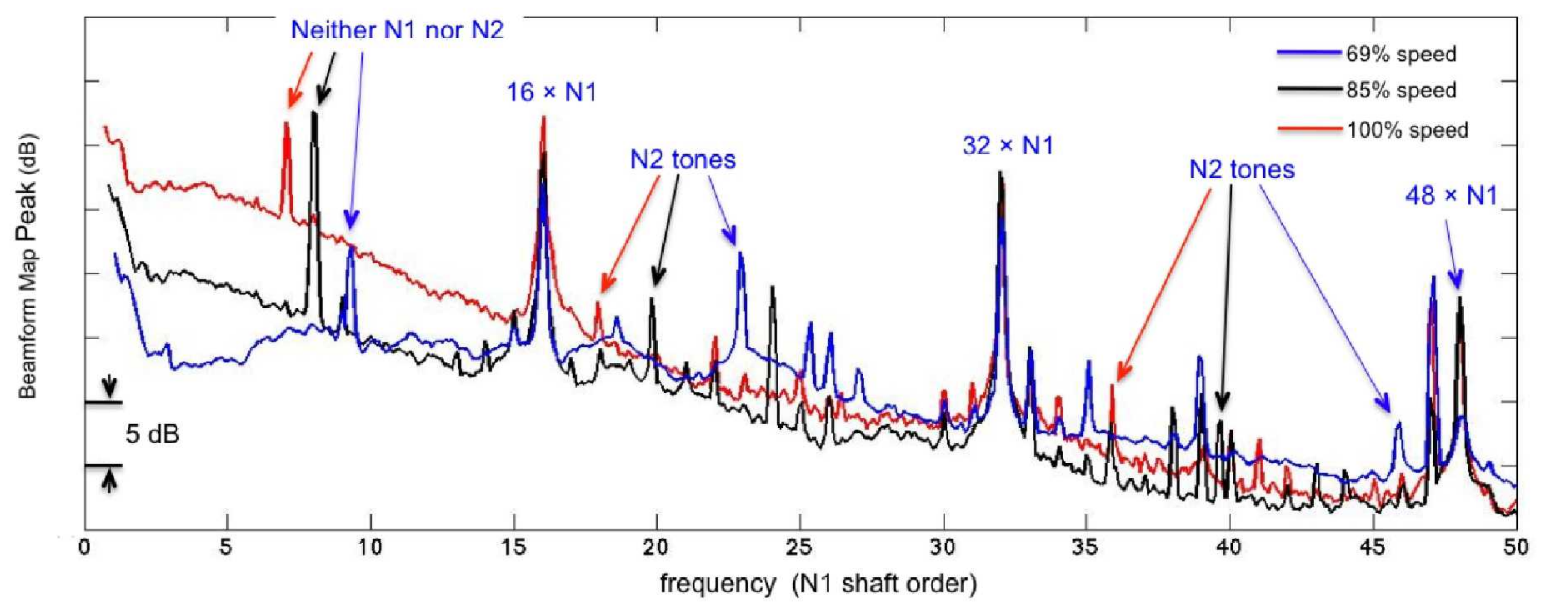

Figure 11.-Nozzle region beamform map peak spectra for 69,85 , and 100 percent speed.

Figure 11 shows beamform map peak spectra generated from data obtained with the array at location 2 for three different fan operating speeds- 69,85 , and 100 percent of the design take off speed. Like the spectra plots discussed above, the data are plotted vs. low speed spool shaft order. Knowing the rotational speed of both the low and high speed spools, it was possible in most cases to determine a correspondence between the tones and the two spools. Tones occurring at integer multiples of the lowspeed spool shaft order are likely to have been generated by a component of the low-speed spool (made up by the fan, a three-stage axial compressor, and a two-stage axial turbine); whereas tones occurring at integer multiples of the high speed spool shaft order are likely to have been generated by a component of that spool (composed of a centrifugal compressor and a single-stage axial turbine). The fundamental and first and second harmonics of the fan show up at 16, 32, and 48 times the low-speed spool shaft order, $\mathrm{N} 1$, respectively. For each operating condition, tones also appear at multiples of the high speed spool shaft order, N2. All the other tones in the spectra appear to be multiples of the low-speed spool shaft order except for the tones marked "neither N1 nor N2" on the figure. One such tone was present in the spectra of each of the eleven different engine operating conditions at which phased array data were acquired. At high power settings, this tone was often as strong or stronger than the fan 1BPF tone and its harmonics. This tone increased in frequency as engine power increased, and it tracked best with the high-speed spool, although it was not an integer multiple of $\mathrm{N} 2$. The exact origin of this tone is unknown, but it may have been caused by vortex shedding off of a protrusion inside the engine. If vortex shedding was the culprit, the protrusion was probably located inside the nozzle region. 


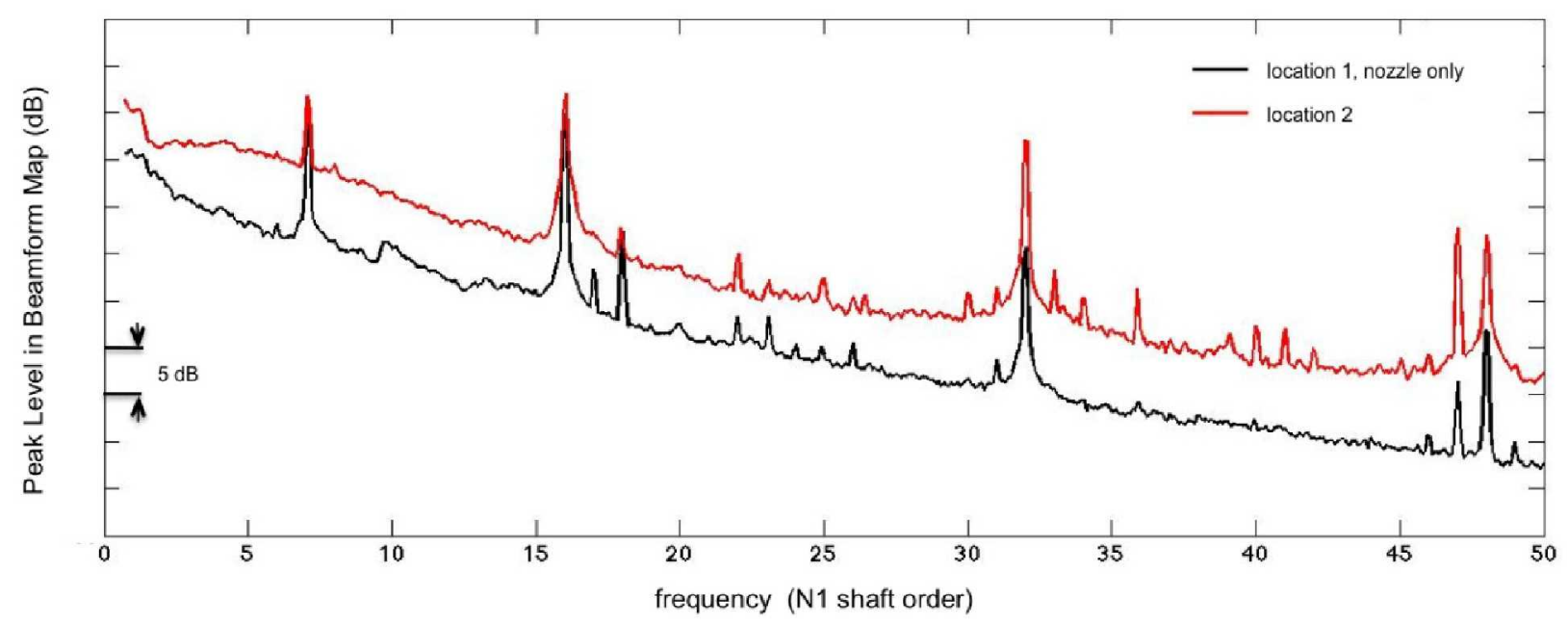

Figure 12.-Comparison of location 1 versus location 2 beamform map peak spectra at 85 percent speed.

(Location 1 spectra were obtained using a nozzle-only ROI).

Figure 12 shows a comparison between nozzle region beamform map peak spectra generated from data at locations 1 and 2 with the engine at 85 percent speed. The location 1 spectrum was generated using the nozzle ROI shown in Figure 6. Consequently, both spectra correspond to data obtained with the array focused only on the nozzle region. Location 1 and location 2 spectra were compared in this way at this and at other engine operating conditions to determine if there was any advantage associated with moving the array closer to the jet in regards to its ability to determine the spectral content of the exhaust flow. The main difference between the two spectra is a difference in level. A difference in level is to be expected considering that both the distance from the jet and the observation angle relative to the jet changed when the array was moved from location 1 to location 2. Other than the shift in level, the two spectra are very similar. This indicates that putting the array at location 1 and using an ROI to "focus" on the nozzle flow was just as effective at determining the spectral content of the exhaust flow as moving the array to location 2 where it was closer to the jet and where it could only image the nozzle flow. This further demonstrates the usefulness of ROIs. They allow the array to be located at a place where it can image noise coming from multiple regions at the same time; then ROIs can be used to determine the spectral content of different regions separately without either 1) having to move the array to "focus" on each region individually or 2) to construct physical acoustic barriers. This can reduce test time.

Figure 13 shows beamform maps generated from data acquired with the microphone array at location 3. Here, the array was at the front of the engine and positioned so that it could detect noise sources coming from the inlet. The array plate was roughly perpendicular to the engine centerline and approximately $182 \mathrm{in}$. upstream of the fan. The results shown in Figure 13 were obtained with the data reduction routine set to search for sources in a vertical plane located at the fan rotor. The beamform maps are overlaid on top of an image taken with the phased array camera; this image shows the "as tested" engine configuration, i.e., it shows the ICD located at the front of the engine. Data are shown for three different fan speeds and seven different $1 / 3$ rd octave frequency bands. Most of the beamform maps show noise coming from two concentric circular rings. Normally the peak level of the inner ring is higher than that of the outer ring.

Figure 14 shows one of the beamform maps of Figure 13 again; it shows the $10,000 \mathrm{~Hz} \mathrm{1/3rd} \mathrm{octave}$ beamform map generated from data acquired with the engine at 100 percent speed. The same map is shown twice. At the left it is overlaid on an image taken with the phased array camera with the engine in it its "as tested" configuration, i.e., with the ICD in place; at the right the data is overlaid on top of an image taken after the ICD was removed. The beamform map at the right shows that the inner ring of noise comes directly from the engine. The outer ring, however, is at too large a diameter to be coming directly from the engine. The outer ring of noise depicted in Figures 13 and 14 is thought to be engine noise reflecting off of the inlet lip of the ICD. 


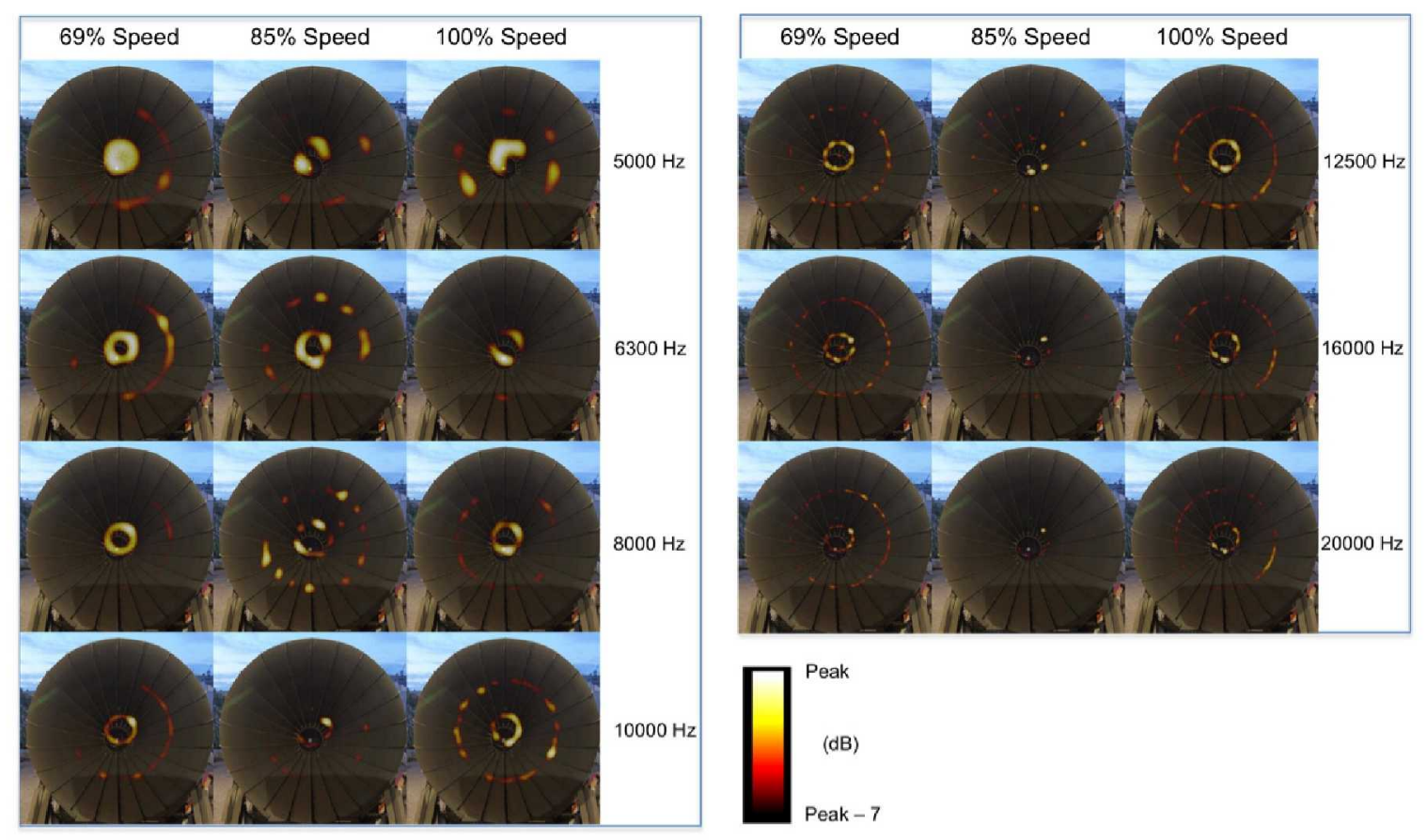

Figure 13.-Beamform maps obtained with the phased array at location 3 showing inlet region noise sources at three engine operating conditions for seven different $1 / 3$ rd octave bands.

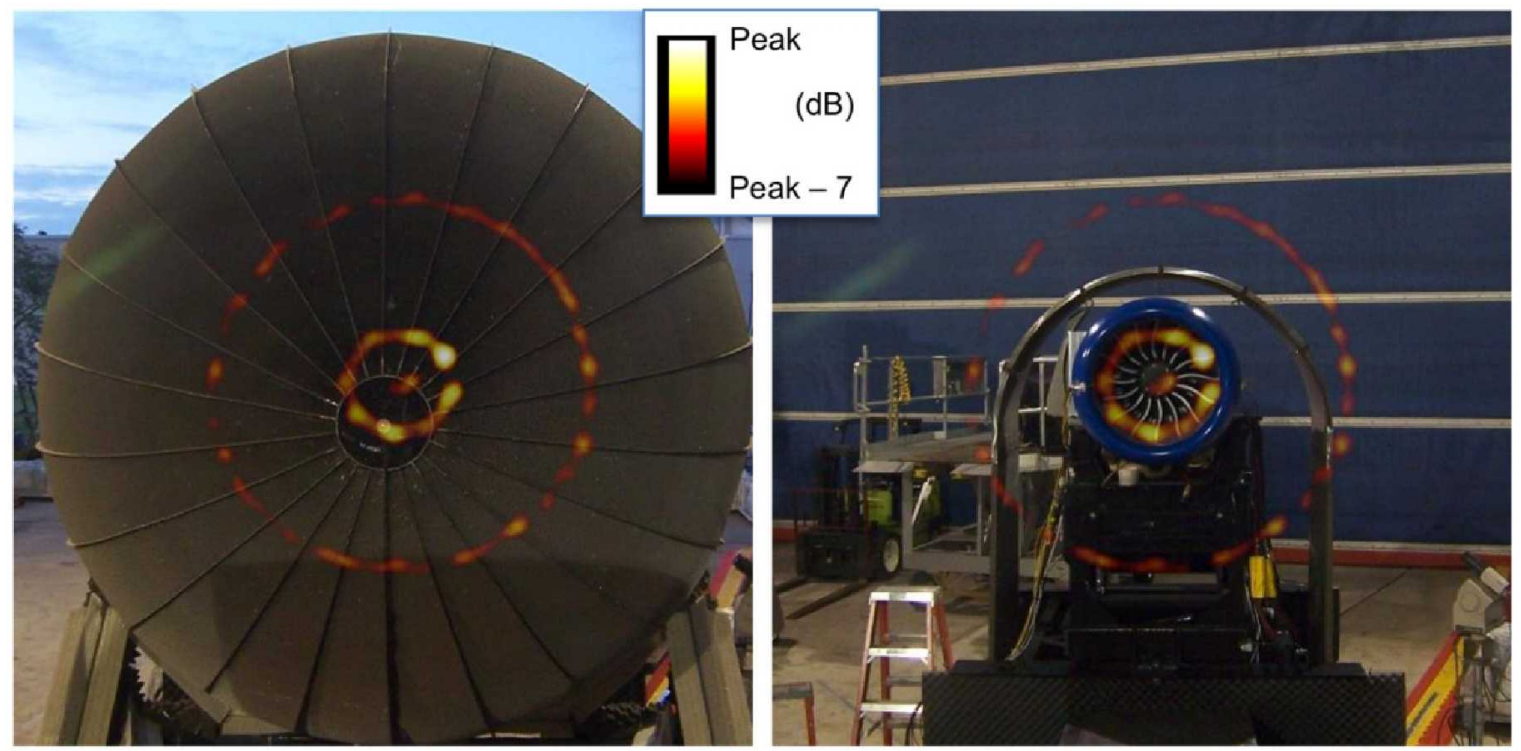

Figure 14.-10,000 Hz 1/3rd octave beamform map acquired at 100 percent speed overlaid on photos taken with (left) and without the ICD (right). 


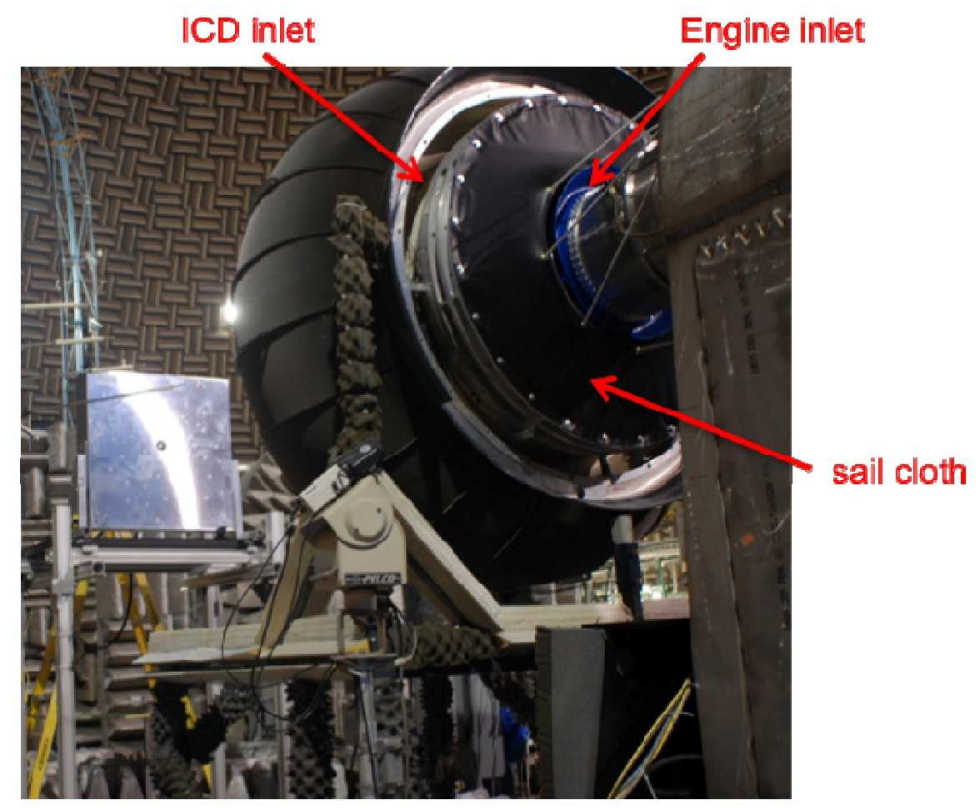

Figure 15.-Photo showing a rear view of the ICD installed on the engine.

The ICD used during this test was not designed for the Williams FJ44 engine. It was designed for the much larger, $4 \mathrm{ft}$-diameter Advanced Noise Control Fan (ANCF) that is tested in the AAPL. Figure 15 shows a photo of an aft-looking-forward view of the ICD installed on the Williams engine. As shown in the photo, the ICD has a large-diameter inlet ring attached to the downstream edge of the honeycomb. The gap between the downstream edge of the ICD inlet ring and the engine inlet (the blue ring shown in the photo) was covered with sail cloth to prevent air from being sucked through the gap. Interference between the ICD and the engine support stand prevented the ICD from being placed at a location where the ICD inlet highlight would be downstream of the engine inlet highlight. Consequently, the ICD inlet served as a hard surface from which noise coming from the engine inlet could reflect. Based on Figure 14, the diameter of the outer noise ring was estimated to be $53 \mathrm{in}$. The inner and outer diameters of the inlet lip of the ICD were measured to be 48 and 64 in., respectively. Consequently, the outer ring of noise shown in the beamform maps of Figures 13 and 14 is thought to be noise that spilled out of the engine inlet and then reflected off the ICD inlet toward the phased array.

The noise reflecting off of the ICD inlet is important since the ICD was intended to be acoustically transparent, i.e., to not alter the noise coming out the engine inlet in any way. Since the array did reflect some of the engine noise, some of the acoustic results obtained during the test are different from what they would have been had the reflection not occurred. As discussed above, one of the objectives of the test was to obtain far field acoustic data which could be used to determine the extent to which a foam metal acoustic liner placed outboard of the fan tip could reduce fan noise relative to a conventional hardwall design. To quantify this effect, far field data were acquired during separate engine runs in which the foam metal and conventional hardwall liners were installed. In order to use this far field data to determine the effectiveness of the foam metal liner, it is necessary to assume that the ICD had the same effect on the noise measurements during both engine runs. Sutliff et al. made this assumption in their report on the effectiveness of the foam metal liner (Ref. 2).

Figure 16 shows $1 / 3$ rd octave beamform maps generated from data obtained with the array at location 3 with the engine operating at 69,85 , and 100 percent speed. These results were generated using the ROI shown in the diagram at the upper right in the figure. This ROI restricted the data reduction routine to search for noise sources within the engine inlet and to ignore the noise reflecting off of the ICD. The photo in the bottom right corner of the figure shows the location of a cylindrical, total temperature probe that was mounted in the inlet upstream of the fan leading edge. Most of the beamform maps at the left in the figure indicate that the location of this probe corresponds to a high noise region. Much of the 


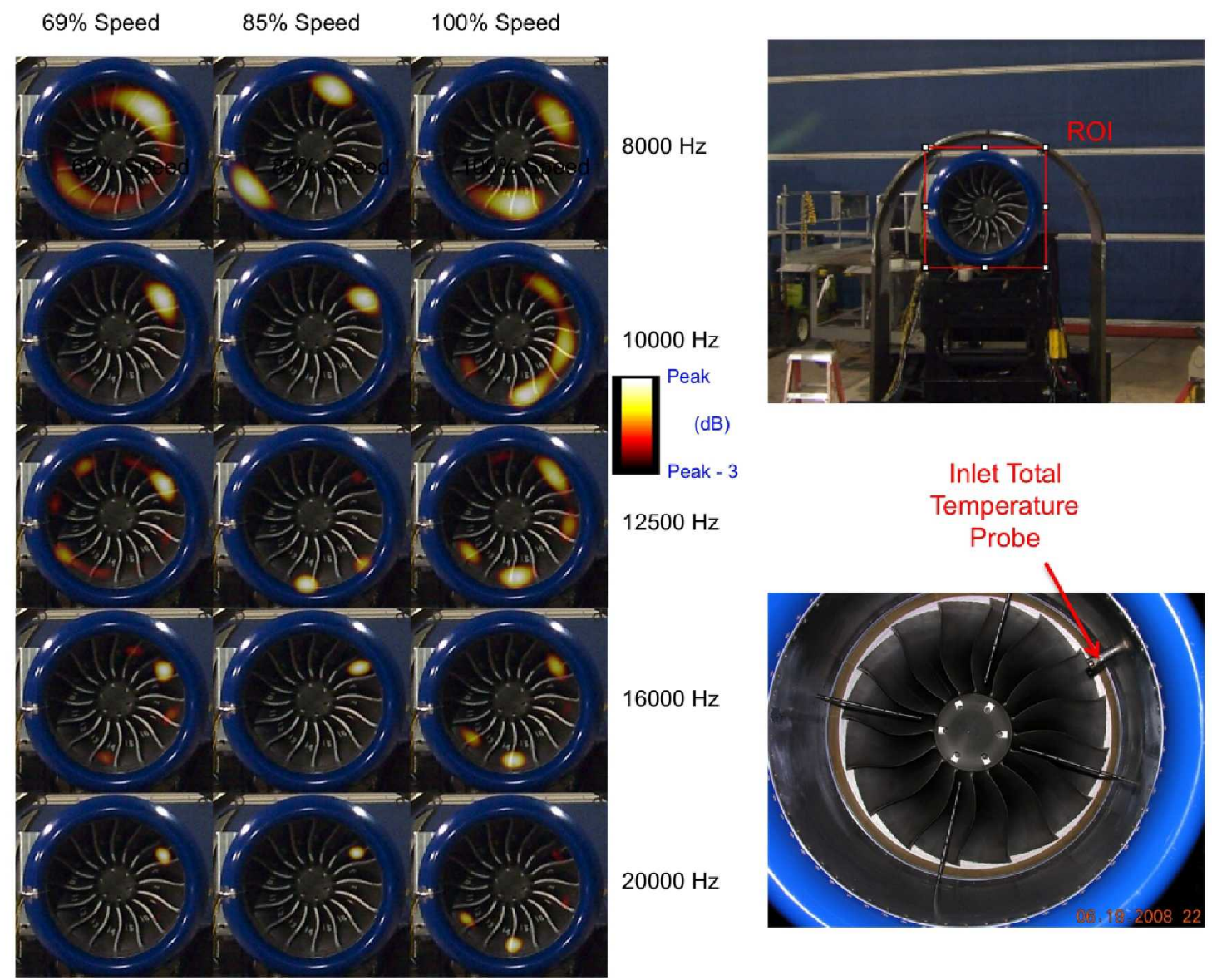

Figure 16. - 1/3rd octave beamform maps showing the inlet total temperature probe location as a high noise region (left). Photo showing the probe near the 2 o'clock position (bottom right).

noise produced in this region is thought to result from the interaction between the probe wake and the downstream fan blades. Noise is produced when the fan blades chop through the vortices shed from the probe. This chopping creates unsteady lift on the blades which, in turn, creates noise. This figure shows $1 / 3$ rd octave beamform maps for center frequencies of $8000 \mathrm{~Hz}$ and above. At lower frequencies the phased array was not able to localize the inlet probe as a dominant noise source. This was not surprising since the ability of any phased array to pinpoint the location of a noise source diminishes as the frequency of the source decreases (Ref. 6).

More evidence of the importance of the probe wake/fan blade interaction is available from unsteady pressure measurements made within the inlet duct. Nine 1/8th in. diameter Kulite pressure transducers were flush-mounted in the duct at the locations shown in Figure 17. Figure 18 shows pressure measurements made with the transducer located at the position designated by the red $\mathrm{X}$ in Figure 17 with the engine operating at 100 percent speed. This transducer was synchronously sampled at 144 measurements per fan rotor revolution for more than 1000 revolutions. The plot provided in Figure 18(a) shows the pressure time histories corresponding to the individual rotor revolutions overlaid on top of one another (in blue). The red line superimposed on top of the blue time traces represents the ensemble average of all of the individual (blue) time traces. The black lines plotted in Figure 18(b) show the result of subtracting the ensemble average (the red line of Fig. 18(a)) from the individual time traces (the blue lines of Fig. 18(a)). The ensemble average was subtracted from the raw data in this manner in an effort to separate the rotor-locked (represented by the red line) and the random (represented by the variation in the black lines) components of the signal. 


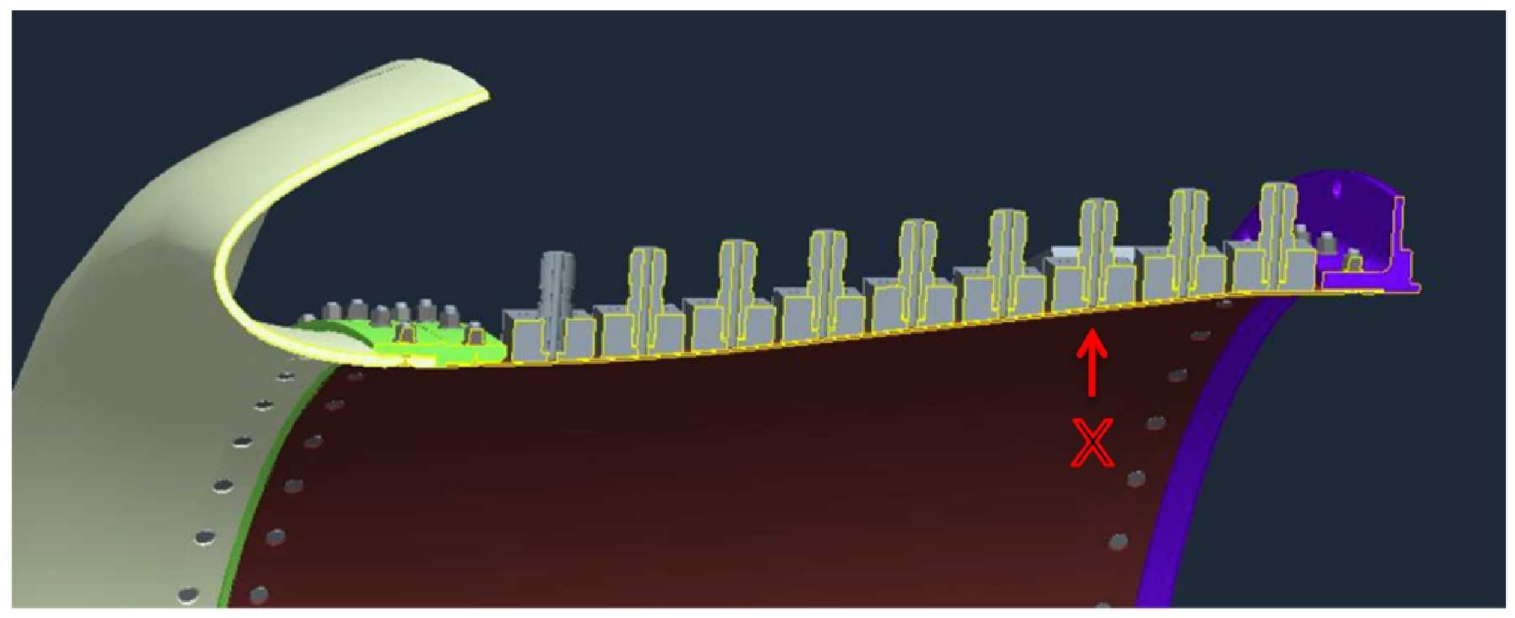

Figure 17.-Schematic showing the location of unsteady pressure transducers in the FJ44 inlet.

The output of the marked transducer is shown in Figure 18.
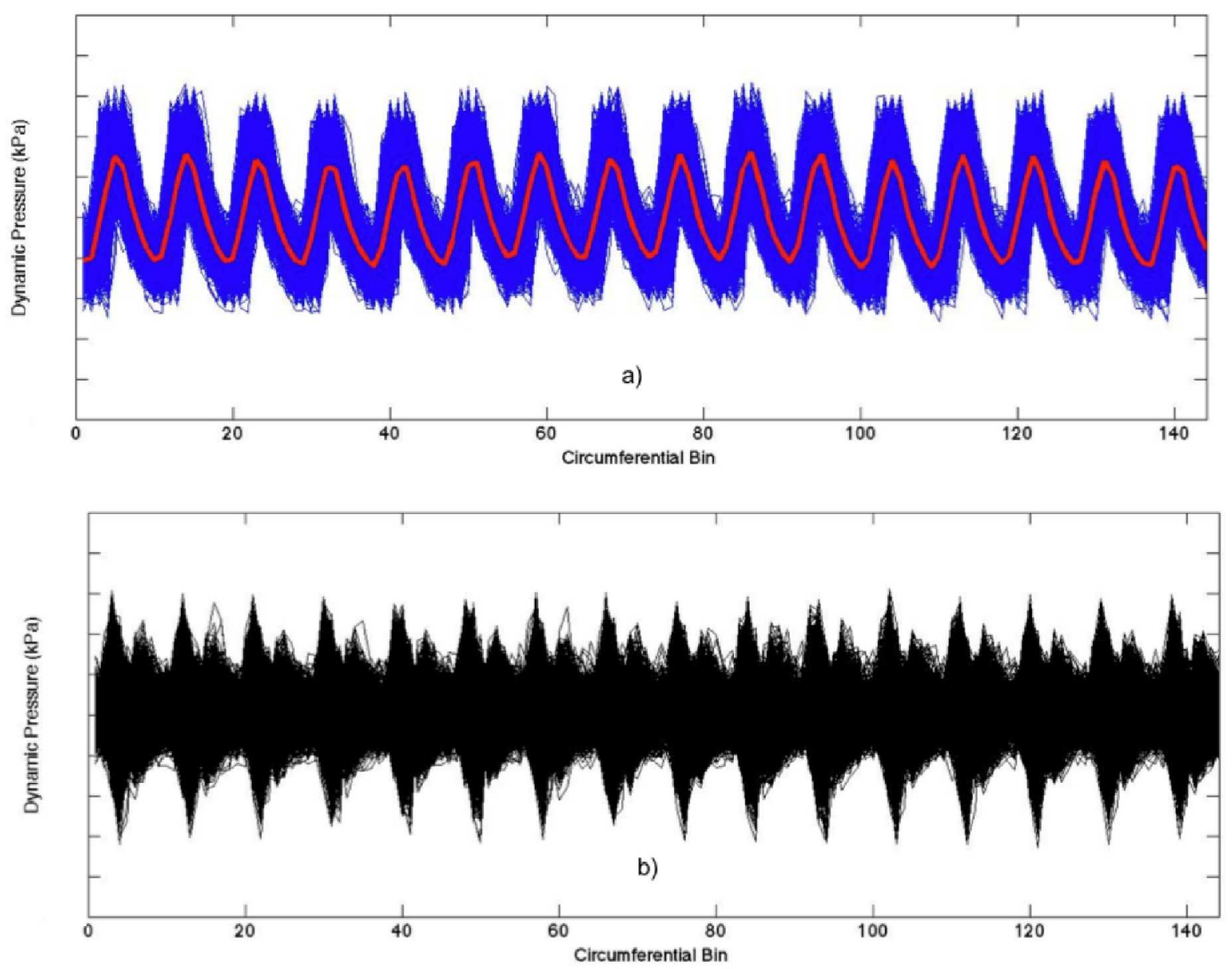

Figure 18.-Dynamic pressure time histories overlaid across the fan rotor revolution. Part a) raw dynamic pressures (blue) and their ensemble average (red). Part b) the result (black) of subtracting the ensemble average (red) from the raw data (blue). 

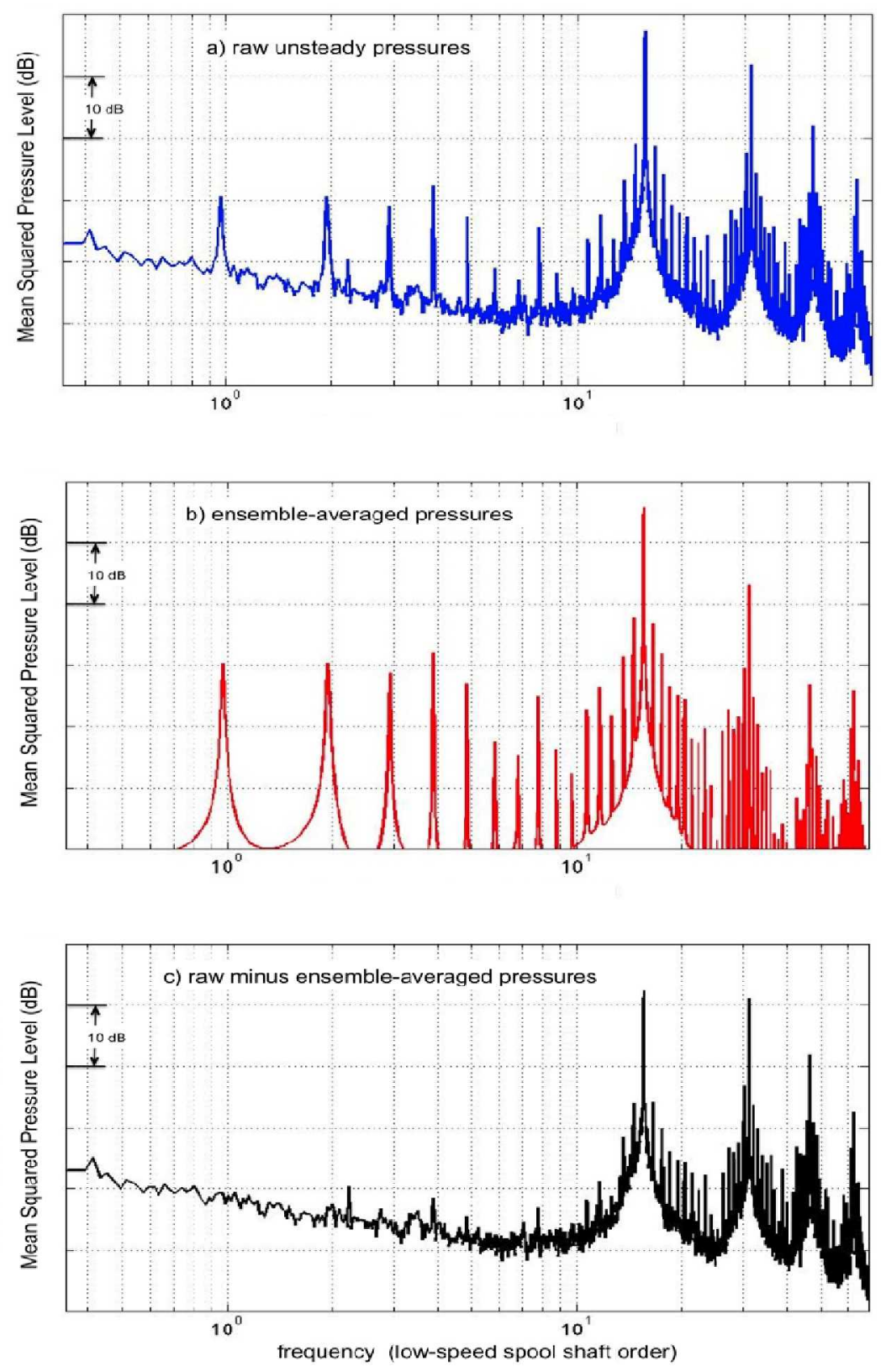

Figure 19.-Power spectra computed from dynamic pressure data. a) raw data, b) ensemble averaged, c) raw minus ensemble averaged.

Figure 19 shows power spectra computed from the raw (blue), the ensemble-averaged (red) and the raw-minus-the-ensemble-averaged (black) time traces of Figure 18. The (red) spectrum shown in Figure 19(b) represents only that part of the total signal that is periodic with respect to the low speed spool shaft frequency. Normally, subtracting the ensemble-averaged time history from the raw signal results in smooth "broadband" spectra that do not contain any tones. As can be seen in Figure 19(c), that was not the case with this unsteady pressure data. It is not clear why this normally reliable method was not very effective at separating the periodic and the random components of the signal (i.e., the tones and the broadband). It has been speculated, however, that it may be due to the unsteady nature of the interaction between the fan blades and the wake shed by the total temperature probe. The unsteadiness associated with the vortices shed from the probe make each fan blade/probe wake interaction slightly 
different. Consequently, these interactions would not all occur at exactly the blade passing frequency; instead they would be slightly out of phase with one another. These phase differences might account for the "haystacking" of the 1BPF tone and its harmonics seen in the spectra plots shown in Figure 19. If this fan blade/probe wake interaction is responsible for the haystacking and for the "leftover" tones that remain in the spectra of Figure 19(c), then these tones suggests that this is a noise source for this engine. The lowest frequency "leftover" tone occurs at the fan blade passing frequency, which is considerably lower than the frequency of the lowest 1/3rd octave image shown in Figure $16(8000 \mathrm{~Hz})$. Consequently, this probe wake/blade interaction appears to be a noise source over a wide frequency range.

\section{Conclusions}

NASA Glenn Research Center's new Array 48 phased array system has been shown to be a very useful diagnostic tool for identifying noise sources in a full-scale Williams International FJ44 engine. The phased array data were spatially filtered to separate noise coming from the inlet and the nozzle of the engine, obviating the need to construct physical acoustic barriers. Noise source localization contour plots (beamform maps) and spectra were used to identify the location and type (tonal vs. broadband) of many of the dominant noise sources within the engine. All but one of the dominant tones occurring within the acoustic spectra could be traced to the engine's low and high speed spools. The phased array data indicate that the Inflow Control Device (ICD) used during this test was not acoustically transparent; instead, some of the noise emanating from the inlet reflected off of the inlet lip of the ICD. Both the phased array data and dynamic pressure measurements made with high frequency response transducers embedded in the inlet suggest that a total temperature probe in the inlet of the engine is a source of fan noise.

\section{References}

1. Cooper, B.A., "A Large Hemi-Anechoic Chamber Enclosure for Community-Compatible Aeroacoustic Testing of Aircraft Propulsion Systems," Journal of the Institute of Noise Control Engineering of the USA, Jan/Feb 1994.

2. Sutliff, D.L., Elliott, D.M., and Jones, M.G., "Acoustic Results from a Foam-Metal Liner Installed Over-the-Rotor of an FJ44 Turbofan Engine," AIAA-2009-3141.

3. Lauer, J.T., McAllister, J., Loew, R.A., Sutliff, D.L., and Hartley, T.C. "FJ44 Turbofan Engine Test in the NASA Glenn Research Center's Aero-Acoustic Propulsion Laboratory," AIAA-2009-0620.

4. Dougherty, R.P., and Podboy, G.G., "Improved Phased Array Imaging of a Model Jet," AIAA-20093186.

5. Podboy, G.G, and Krupar, M.J., "Blade-to-Blade Variations in Shocks Upstream of Both a ForwardSwept and an Aft-Swept Fan," NASA/TM-2006-213445, October 2006.

6. Dougherty, R.P., "Noise Source Imaging by Beamforming," SAE-2008-36-0518. 


\begin{tabular}{|c|c|c|}
\hline \multicolumn{2}{|c|}{ REPORT DOCUMENTATION PAGE } & $\begin{array}{l}\text { Form Approved } \\
\text { OMB No. 0704-0188 }\end{array}$ \\
\hline \multicolumn{3}{|c|}{ 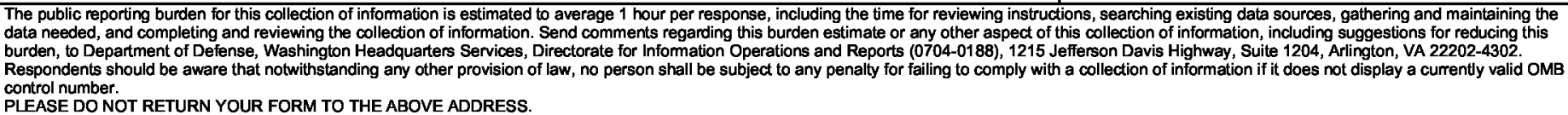 } \\
\hline $\begin{array}{l}\text { 1. REPORT DATE (DD-MM-YYYY) } \\
01-03-2010\end{array}$ & $\begin{array}{l}\text { 2. REPORT TYPE } \\
\text { Technical Memorandum }\end{array}$ & 3. DATES COVERED (From - To) \\
\hline \multirow{3}{*}{\multicolumn{2}{|c|}{$\begin{array}{l}\text { 4. TITLE AND SUBTITLE } \\
\text { Phased Array Noise Source Localization Measurements Made on a Williams International } \\
\text { FJ44 Engine }\end{array}$}} & 5a. CONTRACT NUMBER \\
\hline & & 5b. GRANT NUMBER \\
\hline & & 5c. PROGRAM ELEMENT NUMBER \\
\hline \multirow{3}{*}{\multicolumn{2}{|c|}{$\begin{array}{l}\text { 6. AUTHOR(S) } \\
\text { Podboy, Gary, G.; Horvath, Csaba }\end{array}$}} & 5d. PROJECT NUMBER \\
\hline & & 5e. TASK NUMBER \\
\hline & & $\begin{array}{l}\text { 5f. WORK UNIT NUMBER } \\
\text { WBS 561581.02.08.0318.02 }\end{array}$ \\
\hline \multicolumn{2}{|c|}{$\begin{array}{l}\text { 7. PERFORMING ORGANIZATION NAME(S) AND ADDRESS(ES) } \\
\text { National Aeronautics and Space Administration } \\
\text { John H. Glenn Research Center at Lewis Field } \\
\text { Cleveland, Ohio 44135-3191 }\end{array}$} & $\begin{array}{l}\text { 8. PERFORMING ORGANIZATION } \\
\text { REPORT NUMBER } \\
\text { E-17215 }\end{array}$ \\
\hline \multirow{2}{*}{\multicolumn{2}{|c|}{$\begin{array}{l}\text { 9. SPONSORING/MONITORING AGENCY NAME(S) AND ADDRESS(ES) } \\
\text { National Aeronautics and Space Administration } \\
\text { Washington, DC 20546-0001 }\end{array}$}} & $\begin{array}{l}\text { 10. SPONSORING/MONITOR'S } \\
\text { ACRONYM(S) } \\
\text { NASA }\end{array}$ \\
\hline & & $\begin{array}{l}11 . \text { SPONSORING/MONITORING } \\
\text { REPORT NUMBER } \\
\text { NASA/TM-2010-216228 }\end{array}$ \\
\hline \multicolumn{3}{|c|}{$\begin{array}{l}\text { 12. DISTRIBUTION/AVAILABILITY STATEMENT } \\
\text { Unclassified-Unlimited } \\
\text { Subject Category: } 71 \\
\text { Available electronically at http://gltrs.grc.nasa.gov } \\
\text { This publication is available from the NASA Center for AeroSpace Information, 443-757-5802 }\end{array}$} \\
\hline
\end{tabular}

\section{SUPPLEMENTARY NOTES}

\section{ABSTRACT}

A 48-microphone planar phased array system was used to acquire noise source localization data on a full-scale Williams International FJ44 turbofan engine. Data were acquired with the array at three different locations relative to the engine, two on the side and one in front of the engine. At the two side locations the planar microphone array was parallel to the engine centerline; at the front location the array was perpendicular to the engine centerline. At each of the three locations, data were acquired at eleven different engine operating conditions ranging from engine idle to maximum (take off) speed. Data obtained with the array off to the side of the engine were spatially filtered to separate the inlet and nozzle noise. Tones occurring in the inlet and nozzle spectra were traced to the low and high speed spools within the engine. The phased array data indicate that the Inflow Control Device (ICD) used during this test was not acoustically transparent; instead, some of the noise emanating from the inlet reflected off of the inlet lip of the ICD. This reflection is a source of error for far field noise measurements made during the test. The data also indicate that a total temperature rake in the inlet of the engine is a source of fan noise. 15. SUBJECT TERMS

Phased array; Acoustics; FJ44 engine

\begin{tabular}{|c|c|c|c|c|c|}
\hline \multicolumn{3}{|c|}{ 16. SECURITY CLASSIFICATION OF: } & \multirow{2}{*}{$\begin{array}{l}\text { 17. LIMITATION OF } \\
\text { ABSTRACT } \\
\text { UU }\end{array}$} & \multirow{2}{*}{$\begin{array}{l}\text { 18. NUMBER } \\
\text { OF } \\
\text { PAGES } \\
23\end{array}$} & \multirow{2}{*}{$\begin{array}{l}\text { 19a. NAME OF RESPONSIBLE PERSON } \\
\text { STI Help Desk (email:help@sti.nasa.gov) } \\
\text { 19b. TELEPHONE NUMBER (include area code) } \\
\text { 443-757-5802 }\end{array}$} \\
\hline $\begin{array}{l}\text { a. REPORT } \\
\text { U }\end{array}$ & $\begin{array}{l}\text { b. ABSTRACT } \\
\text { U }\end{array}$ & $\begin{array}{l}\text { c. THIS } \\
\text { PAGE } \\
\text { U } \\
\end{array}$ & & & \\
\hline
\end{tabular}



